Stojevića, Tomislava Ladana, Marina Carića itd.). Konceptualni okvir romana Jasne Horvat jest književnost OULIPA (Ouvroir de littérature potentielle, Radionica potencijalne književnosti), nama najpoznatijih književnika Itala Calvina, Georgesa Pereca te Raymonda Queneaua.

No, možda povijesni aspekt izostaje, ali ne i komparatistički. Paralelnim čitanjima Jasne Horvat s Miloradom Pavićem, Dževadom Karahasanom ili Venkom Andonovskim, uspostavlja se literarno ,pobratimstvo lica u svemiru“. Jedino je i moguće, a i razumno, čitati s jedne strane hrvatsku književnost u kontekstu europskih iskustava, a s druge, staviti nas u logičan jezični areal onoga što zovemo regionalnom ili južnoslavenskom književnošću. Budući da postmodernizam inzistira na razlikama, Kos-Lajtman se fino poigrala u Poetici oblika i ukazala na sličnosti te na idejne bliskosti različitih eksperimentu sklonih književnika, bez obzira na to gdje obitavali. Ideja mreže stoga nije zbirka rupa nego nit vodilja koja u različitim kulturama nitima povezuje radikalne oblike mašte, ludizma, invencije.

Sanjin Sorel

\title{
Die spezifische Ausprägung des Initiationsromans in der Kinderliteratur
}

Hadassah Stichnothe. 2017. Der Initiationsroman in der deutsch- und englischsprachigen Kinderliteratur. Heidelberg: Universitätsverlag Winter. 300 Seiten. ISBN 978-3-8253-6766-4

DOI: 10.21066/carcl.libri.2018-07(01).0012

Auf Grundlage seiner Beschäftigung mit dem modernen amerikanischen Roman stellte Peter Freese in seinem Werk Die Initiationsreise. Studien zum jugendlichen Helden im modernen amerikanischen Roman mit einer exemplarischen Analyse von J. D. Salingers ,, The Catcher in the Rye “ fest, dass Initiationsromane des 20. Jahrhunderts „verwirrte und suchende Heranwachsende in [...] prekäre[r] Grenzstellung zwischen der noch nicht verlorenen Unschuld des Kindes und der noch nicht gefundenen Erfahrung der Erwachsenen, [die] den Übergang von der einen Welt in die andere [...] leisten, den Fall durch Wissen zur Reife [...] erleiden, [...] um initiation zu leisten, [...]" thematisieren (1971: 23-24). Neulich (2014) beschäftigte sich Nicole Gast mit dem Reifewerden im neueren deutschen Roman in ihrer Dissertation Erwachsenwerden im deutschen Pop-Roman. Der Reifeprozess der Protagonisten in Faserland, Soloalbum \& Co. Eine vergleichende Studie deutsch- und englischsprachiger Initiationsromane präsentiert dagegen Hadassah Stichnothe, indem sie in ihrer Dissertation Der Initiationsroman in der deutsch- und englischsprachigen Kinderliteratur die spezifische Ausprägung des Initiationsromans in der Kinderliteratur thematisiert. Der Band ist 2017 in der Serie Studien zur europäischen Kinder- und Jugendliteratur/Studies in European Children's and Young Adult Literature erschienen.

Stichnothes formal aus zwei Teilen bestehende Monografie ist strukturell in sieben inhaltliche Einheiten gegliedert, wobei der erste Teil die theoretische Grundlage und der längere zweite Teil die aus verschiedenen Perspektiven und auf verschiedene Themen bezogenen Textanalysen beinhaltet. Ähnlich wie Gast (2014) setzt sich Stichnothe mit dem anthropologischen und literaturwissenschaftlichen Begriff Initiation und der Erörterung 
spezifischer Figurenkonstellationen (wie z. B. Mentorfigur usw.) wie auch mit den Schauplätzen der Initiation auseinander. Stichnothes erster theoretischer Teil bietet die Definition des Begriffs Initiation und ihre Verwendung in verschiedenen wissenschaftlichen Disziplinen mit besonderer Berücksichtigung der Forschung der Kinderliteratur dar. Darüber hinaus wird hier auf die Unterschiede zwischen den Gattungen Initiationsroman und Bildungs-, Entwicklungs- und Adoleszenzroman hingewiesen wie auch auf die Unterschiede zwischen männlicher und weiblicher Initiation. Somit bereitet Stichnothe den Weg zu der eigenen Arbeitsdefinition des Initiationsromans mithilfe der Theorie des Sujets nach Jurij Lotman vor, die dann im zweiten textanalytischen Teil als Grundlage für die ausführliche und komparatistische Beschäftigung mit dem Initiationsroman fungiert.

Der analysierte Korpus beinhaltet Werke von Klassikern wie Otfried Preußler, Frances Hodgson Burnett und Michael Ende, darüber hinaus die von Nils Mohl, Wolfgang Herrndorf, Alina Bronsky, Louise Erdrich, Rumer Godden, Lloyd Alexander, Ursula K. Le Guin, Katherine Allfrey, Anna Jürgen, A. M. Homes, James Krüss, Mirjam Pressler und Iva Procházková. Die Studie ermöglicht somit, einen transversalen Überblick über Begriffe wie Eros und Thanatos, phantastische Elemente, indigene Kulturen, Weiblichkeit, Männlichkeit, Figurenkonstruktion und Raumkonzepte in Initiationsromanen zu gewinnen. Gerade die Untersuchung der räumlichen Dimension und damit verbundener Grenzüberschreitungen aus der Kindheit in das Erwachsensein (wie beispielsweise der Abstieg in die Unterwelt, die Rückkehr in den Mutterleib, die Nachtmeerfahrt, das Motiv der grünen Welt) wird in der Analyse von Figurenkonstellationen (Mentorfiguren, hybride Figuren, Grenzgängerund Tomboy-Figuren) eingesetzt. Die Analyse beschränkt sich auf Romane des 20. und 21. Jahrhunderts und untersucht den Initiationsroman als ein „mehrheitlich heteronormatives Genre“ (Stichnothe 2017: 278), das sich im deutschsprachigen Bereich als ,überraschend politisch“ (ebd.: 279) erweist.

Die Monografie ist insofern nützlich, als sie die bisherigen Erkenntnisse über den Initiationsroman erweitert und durch eine vergleichende Darstellung auf die Ähnlichkeiten und Unterschiede zwischen den englischsprachigen und den deutschsprachigen Initiationsromanen hinweist. Es kann als eine Besonderheit dieser Monografie hingewiesen werden, dass die ritualisierte Initiation im westlichen Kulturkreis zeit-, kultur-, aber auch geschlechtsabhängig ist, wobei diese Faktoren auf die Strukturierung von Raumkonstruktionen in der Literatur einwirken.

Sonja Novak 